\title{
PEMETAAN STORE DESIGN DAN VISUAL MERCHANDISING DISTRO DI KOTA BANDUNG
}

\author{
Jurry Hatammimi \& Brhiyawan RH Cendekia \\ Fakultas Ekonomi \& Bisnis, Universitas Telkom \\ Jl. Telekomunikasi, Terusan Buah Batu, Dayeuh Kolot, Bandung 40257 \\ jurryhatammimi@telkomuniversity.ac.id / jurryhatammimi@gmail.com
}

\begin{abstract}
One of the evidence of creative industry growth in fashion sector in the city of Bandung is the establishment of many distro or distribution outlet. There are 4 distro that has the highest sales level, i.e Ouval Research, Unkl347, Dloops, and Black Id. The four distro were trying to show differentiation in terms of store design and visual merchandising to make up the store uniqueness and influencing buying behavior. Beside there is no research about the mapping of distro in the city of Bandung yet, especially about their store design and visual merchandising, this study will also show the difference of the four distro even though they have some similarities. This study aims to determine the perceptual map of store design and visual merchandising which applied by each distro. By using Multi Dimensional Scaling, there are consumer assessment in making perceptual maps include shopping convenience, easy to find goods, shopping experience, signage, entrance, cash wraps, promotional aisle, windows, fitting room, traffic flow, alignment rack with the theme, the attractiveness of presentation techniques, and impulse purchase. The research shows Ouval Research superior in largely indicators namely shopping convenience, easy to find goods, shopping experience, signage, entrance, promotional aisle, windows, fitting room, the attractiveness of presentation techniques, and impulse purchase. Unkl347 win in two indicators namely cash wraps and alignment rack with the theme. Dloops only win in the traffic flow indicator. Black Id ranks fourth at all indicators.
\end{abstract}

Keywords: Perceptual Map, Store Design, Visual Merchandising, Distribution Outlet 


\section{PENDAHULUAN}

Distribution store atau Distro yang dikenal oleh masyarakat kota besar di Indonesia lebih dimaknai sebagai tempat dijualnya pakaian dengan merek tertentu dan dijual dalam jumlah yang terbatas. Menurut Bank Indonesia (2008:1-2), distro bermula dari Bandung sejak tahun 1993 namun baru berkembang pada tahun 1998.

Kota Bandung pada tahun 2012 memiliki jumlah penduduk sebesar 2.455.517 orang (BPS Kota Bandung 2013). Menghubungkan dengan target utama pasar distro yaitu mereka yang berusia sekitar 15 - 29 tahun, data menunjukkan bahwa jumlah penduduk Kota Bandung di rentang usia tersebut adalah berjumlah 264.190 orang atau $10,76 \%$ dari total penduduk Kota Bandung. Dengan melihat persentase tersebut, usaha distro masih dianggap berpotensi untuk terus dikembangkan.

Berdasarkan hasil Survei Sosial Ekonomi Daerah 2010 (BPS Kota Bandung 2012), tingkat rata-rata konsumsi pakaian per kapita sebulan penduduk Kota Bandung pada tahun 2010 sebesar 2,67\% dari total pengeluaran atau Rp. 23.783. Tingkat konsumsi itu berada di posisi ke-3 jumlah pengeluaran terbanyak dari sub golongan bukan makanan.

Jumlah konsumsi pakaian tersebut jika dihitung per tahun maka bernilai Rp. 285.396 per orang. Jika menghitung proyeksi konsumsi pakaian khusus bagi penduduk Kota Bandung yang berusia 15 - 29 tahun, maka akan tercatat nilai sebesar Rp. 75.398.769.240 dalam satu tahun. Hal ini jelas merupakan potensi ekonomi yang sangat besar.

Sektor pariwisata pun memiliki andil meningkatkan potensi ekonomi bagi distro. Menurut Dinas Kebudayaan dan Pariwisata Kota Bandung, pada tahun 2011 terdapat 6.712.824 wisatawan yang berkunjung ke Bandung. Data tahun 2010 menunjukkan bahwa wisata belanja (fashion) adalah jenis wisata yang paling diminati. Tercatat 2.401 .312 wisatawan yang berkunjung ke Kota Bandung melakukan wisata belanja (fashion). Data tersebut menunjukkan bahwa potensi pasar bidang fashion di kota Bandung adalah sangat besar.

Dinas Koperasi, UKM, Perindustrian, dan Perdagangan (KUKM \& Perindag) Kota Bandung mencatat ada tujuh jenis tempat yang dikategorikan sebagai pasar modern yang merupakan saluran distribusi bidang fashion seperti tertera pada Tabel 1.

Tabel 1

Data Potensi Pasar Modern di Kota Bandung

\begin{tabular}{|c|l|r|}
\hline No. & \multicolumn{1}{|c|}{ Kategori } & Jumlah \\
\hline 1. & Supermarket & 27 \\
\hline 2. & Hypermarket & 9 \\
\hline 3. & Departement Store & 16 \\
\hline 4. & Pusat perdagangan & 7 \\
\hline 5. & Mall & 22 \\
\hline 6. & Distro & 135 \\
\hline 7. & Factory Outlet & 98 \\
\hline \multicolumn{2}{|c|}{ Jumlah } & 314 \\
\hline
\end{tabular}

Sumber: Dinas KUKM dan Perindag Kota

Bandung, 2012

Seluruh fashion retail yang tercatat dalam Tabel 1 memiliki cara dan strategi khusus untuk bersaing satu sama lain tentunya demi memenangkan persaingan. Persaingan yang ada terjadi lebih kuat lagi di dalam kategori yang sama.

Penelitian Dewi (2010:6) menyebutkan paling tidak ada 32 distro di kota Bandung yang memiliki umur lebih dari 4 tahun pada tahun 2009. Selain itu diketahui pula tingkat 
permintaan produk distro di Kota Bandung pada tahun 2009 adalah sebagaimana tercantum pada Tabel 2. Empat distro di Kota Bandung yang memiliki jumlah permintaan terbanyak. Distro tersebut adalah Ouval Research, Unk1347, Dloops, dan Black Id.

Distro merupakan fashion store yang menjual produknya sendiri dan sangat menonjolkan sisi eksklusifitas store design. Setiap distro memiliki cara masing-masing dalam menarik konsumen dari segi layout toko, display produk, desain interior maupun eksterior.

Penelitian Nento (2005:92) menjelaskan bahwa ada korelasi yang kuat antara visual merchandising dengan minat beli konsumen pada Flexi Center Dago, begitu juga Stiefi (2012:87) menambahkan terdapat hubungan yang sangat kuat antara store layout dengan minat beli. Hasil penelitian Nento (2005) \& Stiefi (2012) sejalan dengan teori yang dikatakan oleh Levy \& Weitz (2009:507) bahwa ada pengaruh yang signifikan antara perilaku membeli dengan store design \& merchandise presentation.

Dibandingkan fashion retail lainnya, keberadaan distro di Kota Bandung adalah yang terbanyak dengan jumlah 135 distro (Dinas KUKM \& Perindag Kota Bandung 2012). Mengingat perkembangan distro yang pesat dan sebagai fashion retail di Kota Bandung dengan jumlah terbanyak saat ini, penelitian terkait store design dan visual merchandising perlu dilakukan terhadap distro. Empat distro dengan permintaan terbanyak (Ouval Research, Unk1347, Dloops, dan Black Id) dapat dijadikan obyek penelitian tersebut.

Tabel 2

Permintaan Produk Distro Per 2009

\begin{tabular}{|c|l|c|}
\hline No. & \multicolumn{1}{|c|}{ Nama Distro } & Jumlah Permintaan (unit) \\
\hline 1 & Ouval Research & 38.401 \\
\hline 2 & Unkl 347 & 37.579 \\
\hline 3 & Dloops & 36.230 \\
\hline 4 & Black Id & 30.237 \\
\hline 5 & Blankwear & 26.720 \\
\hline 6 & Kuya Gaya & 26.375 \\
\hline 7 & Air Plane System & 25.632 \\
\hline 8 & Cosmic & 23.651 \\
\hline 9 & Skaters & 23.348 \\
\hline 10 & Green Light & 22.654 \\
\hline 11 & Flashy & 21.935 \\
\hline 12 & Yodium Freedom & 21.206 \\
\hline 13 & Evil & 20.671 \\
\hline 14 & Order & 19.721 \\
\hline 15 & Wadezig & 18.810 \\
\hline 16 & 3 Second & 18.237 \\
\hline 17 & Proshop & 17.997 \\
\hline 18 & Coffee Park & 16.325 \\
\hline 19 & Provider & 15.190 \\
\hline 20 & Diery & 14.237 \\
\hline 21 & Invictus & 14.197 \\
\hline & & \\
\hline
\end{tabular}




\begin{tabular}{|c|l|c|}
22 & Mountly & 13.590 \\
\hline 23 & Volta Folks & 13.436 \\
\hline 24 & Omnium & 13.001 \\
\hline 25 & Gummo & 12.826 \\
\hline 26 & Black Jack & 11.110 \\
\hline 27 & Rock Star & 10.798 \\
\hline 28 & God Inc & 10.540 \\
\hline 29 & Badger & 8.208 \\
\hline 30 & Frontline & 8.125 \\
\hline 31 & Rollink & 6.761 \\
\hline 32 & Tee Company & 6446 \\
\hline
\end{tabular}

Sumber: Dewi (2010:6)

Keempat distro tersebut dipilih juga karena memiliki kesamaan segmentasi berdasarkan usia, tingkat ekonomi, kedekatan wilayah penjualan, dan kesamaan dalam konsep yang mengusung tema urban. Selain karena belum adanya penelitian yang melakukan pemetaan terhadap distro di Kota Bandung khususnya terhadap empat distro dengan permintaan terbanyak pada unsur store design dan visual merchandising-nya, penelitian ini ingin pula menunjukkan perbedaan posisi keempat distro tersebut berdasarkan persepsi konsumennya meskipun keempatnya memiliki beberapa kesamaan.

Berdasarkan beberapa hal tersebut, penelitian ini bertujuan untuk mengetahui peta persepsi konsumen terhadap store design dan visual merchandising distro Ouval Research, Unk1347, Dloops, dan Black Id.

\section{LANDASAN TEORI}

\section{Retail Strategy}

Levy \& Weitz (2009:134) menjelaskan arti retail strategy adalah pernyataan yang mengidentifikasikan target pasar yang dituju retailer, format retail yang di desain untuk memuaskan kebutuhan target pasarnya, serta perencanaan dalam membuat sustainable competitive advantage yang bisa bertahan dalam jangka waktu yang lama serta tidak mudah ditiru oleh pesaing. Menurut Levy \& Weitz (2009:134) retail format menjelaskan tentang operasional perusahaan berkaitan dengan retail mix, antara lain tipe merchandise dan jasa yang ditawarkan, penetapan harga, program promosi dan periklanan, desain toko dan visual merchandising, tipe lokasi, serta customer service.

\section{Store Design dan Visual Merchandising}

Store design dan visual merchandising termasuk ke dalam bagian store management yang mempengaruhi keunikan toko. Perusahaan sebisa mungkin memberikan keunikan tersendiri serta membuat desain yang menarik agar suasana toko yang tercipta mendukung proses belanja konsumen. Levy \& Weitz (2009:508) menjelaskan bahwa store design memiliki peran yang penting dalam membuat serta memperkuat brand image.

Menurut Levy \& Weitz (2009:508) tujuan dari desain toko adalah untuk mengimplementasikan strategi retailer, mempengaruhi perilaku membeli, memberikan fleksibilitas, mengontrol biaya desain dan perawatan, serta memenuhi aspek legal. 
a. Implementasi strategi retailer

Desain toko harus selaras dengan kebutuhan target pasar yang ditentukan karena desain toko merupakan salah satu bagian dari positioning untuk membentuk image perusahaan dalam pikiran konsumen.

b. Mempengaruhi perilaku pembeli

Menurut Levy \& Weitz (2009:509) desain toko yang baik akan menarik konsumen untuk berkunjung, mempermudah konsumen untuk menemukan barang yang dicari, memotivasi dan memberi dorongan kepada konsumen untuk melakukan pembelian lain yang tidak direncanakan sebelumnya, serta memuaskan konsumen dengan pengalaman berbelanja yang menyenangkan.

c. Fleksibilitas

Fleksibilitas yang dimaksud dalam hal ini adalah kemudahan untuk mengganti komponen didalam toko jika sewaktu-waktu ada perubahan konsep toko, kehadiran barang baru, serta promo-promo yang diadakan retailer.

d. Mengontrol biaya

Perbedaan produk yang dijual berarti berbeda pula desain toko yang dibuat. Hal ini akan mempengaruhi kebijakan perusahaan dalam mengimplementasikan desain toko. Sebagai contoh Levy \& Weitz (2009:510) menjelaskan dengan mengeluarkan biaya lebih pada faktor pencahayaan berarti akan membuat produk yang dipajang lebih menarik. Hal ini diharapkan akan meningkatkan penjualan produk tersebut.

e. Aspek legal

Beberapa negara menetapkan kebijakan perlindungan terhadap orang dengan kebutuhan khusus. Hal ini tentu saja berpengaruh pada desain toko yang harus dapat mengakomodir semua golongan tak terkecuali orang dengan kebutuhan khusus.

f. Design trade-offs

Trade-offs ini berkaitan dengan mengimplementasikan alternatif desain yang menguntungkan dengan menghilangkan beberapa keuntungan lain.

Levy \& Weitz (2009:512) memberikan salah satu contoh trade-off yang dihadapi oleh retailer yaitu memberi dorongan kepada konsumen untuk lebih konsumtif atau memberi kemudahan dalam mencari produk. Sebagai contoh barang $\mathrm{Z}$ yang memiliki penjualan tinggi ditaruh di ujung toko dengan harapan konsumen yang ingin membeli barang $\mathrm{Z}$ berjalan melewati beberapa rak produk agar ada hasrat untuk membeli produk lain, namun hal ini justru akan mengurangi kenyamanan konsumen yang hanya ingin membeli barang Z. Alternatif lain bisa diimplementasikan dengan menaruh barang Z di depan toko untuk memberikan kenyamanan kepada konsumen dengan pertimbangan tidak akan ada konsumen yang berkeliling toko terlebih dahulu sebelum membeli barang $\mathrm{Z}$.

\section{Store Design}

Store design menurut Levy \& Weitz (2009:508) mencakup layout, signage, serta feature areas.

\section{a. Layouts}

Layout mencakup susunan bagian toko yang terbagi atas wilayah tertentu yang memisahkan jenis produk atau fungsi tertentu. Dari penjelasan yang dikemukakan oleh Levy \& Weitz (2009:512-515) layout dibuat untuk memudahkan konsumen dalam mencari barang, mengefisiensikan biaya melalui penggunaan ruang yang optimal, mengarahkan konsumen pada lokasi tertentu di dalam toko, memberikan kenyamanan berbelanja, serta memberikan pengalaman belanja yang menyenangkan.

Layout toko dapat merepresentasikan tema toko serta image yang ingin dimunculkan. Layout dapat di sesuaikan dengan kebutuhan toko berdasarkan barang yang dijual. 
Menurut Levy \& Weitz (2009:512-515) Layout toko dapat dibuat seperti lorong-lorong, dibentuk asimetris, atau dikondisikan seperti jalur agar konsumen melewati seluruh bagian toko mengikuti layout yang dibentuk.

b. Signage \& Graphics

Signage merupakan penanda suatu produk atau penanda arah yang menunjukan suatu tempat di dalam toko. Menurut Levy \& Weitz (2009:516) selain dapat membantu konsumen mencari bagian departemen, produk, dan informasi, graphics seperti panel foto juga harus mencirikan karakteristik sebuah toko.

Ada beberapa fungsi komunikasi visual dalam implementasi di sebuah toko, antara lain seperti yang diungkapkan Levy \& Weitz (2009:516-517):

(1) Lokasi

Signage dapat digunakan untuk menunjukan lokasi suatu tempat atau produk tertentu.

Biasanya signage penunjuk lokasi digunakan oleh toko yang memiliki lahan yang luas seperti mall atau suatu gedung.

(2) Category signage

Category signage digunakan untuk menunjukan tempat sesuai dengan tipe produk. Levy \& Weitz (2009:516) menjelaskan bahwa category signage digunakan antar sektor yang ada dalam toko untuk membedakan tipe produk, category signage biasanya ditempatkan dekat dengan barang yang ditawarkan.

(3) Promotional signage

Tipe signage ini untuk menunjukan promosi atau diskon yang sedang diselenggarakan oleh toko. Levy \& Weitz (2009:516) menjelaskan biasanya promotional signage ditempatkan di jendela depan toko agar orang-orang tahu mengenai promo yang sedang berlangsung.

(4) Point of sale

Point of sale ditempatkan di dekat produk sehingga konsumen dengan mudah mengetahui harga dan informasi detail produk, seperti diskon dan lain sebagainya (Levy \& Weitz 2009:516).

(5) Lifestyle image

Levy \& Weitz (2009:517) menjelaskan bahwa lifestyle image dapat bervariasi seperti gambar orang atau suatu tempat. Jenis signage ini bertujuan untuk membuat mood yang mendorong konsumen untuk membeli.

Saat ini signage tidak hanya dalam bentuk media konvensional tetapi juga dalam bentuk digital. Media digital dapat lebih menarik konsumen karena sifatnya yang dinamis. Beberapa contoh digital signage antara lain video clip serta penunjuk harga digital (Levy \& Weitz 2009:517)

c. Feature Areas

Feature areas menurut Levy \& Weitz (2009:518) adalah area di dalam toko yang dibentuk agar menarik perhatian konsumen. Feature areas juga bisa dijadikan sebagai petunjuk arah bagi konsumen. Feature areas dibagi menjadi entrances (jalan masuk), freestanding display, cash wraps (kasir), end caps, promotional aisle/area (area promosi), walls (tembok), windows (jendela/etalase toko), dan fitting rooms (ruang ganti) (Levy \& Weitz 2009:518-521).

(1) Entrances (jalan masuk)

Pada bagian ini biasanya dipajang hal-hal mengenai produk yang dijual di toko. Toko ponsel memajang ponsel dengan teknologi terkini, toko pakaian memajang baju keluaran terbaru, dan seterusnya. Fetterman \& O’Donnel (2006) dalam Levy \& Weitz (2009:518) menerangkan bahwa area ini disebut area decompression zone karena merupakan tempat orang berpindah dari lingkungan luar ke lingkungan dalam toko. 
Entrances area juga merupakan tempat untuk menarik konsumen agar mau berkunjung.

(2) Freestanding displays

Bagian ini merupakan rak atau manekin yang dipajang pada lorong untuk tujuan menarik konsumen (Levy \& Weitz 2009:518). Levy \& Weitz (2009:518) menambahkan freestanding displays bisa merupakan boneka (manekin), barang terbaru, atau barang paling menarik yang dimiliki toko. Sifat freestanding display hampir sama dengan bagian entrances yaitu untuk menarik konsumen.

(3) Cash wraps (kasir)

Tempat ini merupakan tempat di mana orang-orang melakukan pembayaran atas barang yang dibelinya. Seringkali pengunjung mengantri dan menunggu cukup lama untuk melakukan pembayaran. Menurut Levy \& Weitz (2009:518-519) dikarenakan banyak pengunjung yang menunggu maka dibagian ini retailer biasanya memajang produk-produk yang mendorong konsumen untuk membelinya seperti permen, majalah, serta pisau cukur.

(4) End caps

Menurut Levy \& Weitz (2009:519) end caps merupakan bagian yang ada di ujung rak, bisa berupa pajangan, produk-produk promosi, atau poduk musiman. Retailer memanfaatkan bagian ini juga untuk mendorong konsumen melakukan pembelian lebih banyak.

(5) Promotional aisle / area (area promosi)

Area ini merupakan area khusus yang disediakan retailer untuk barang-barang yang sedang dalam masa promosi atau barang yang bersifat musiman. Area ini dapat berganti setiap minggu atau dalam periode yang singkat sesuai dengan jangka waktu promosi yang berlaku.

(6) Walls (tembok)

Area tembok juga dapat dijadikan untuk memajang produk yang dijual. Kelebihan dari penggunaan tembok adalah retailer dapat menyisakan banyak ruang untuk dijadikan tempat hilir mudik konsumen atau dimanfaatkan sebagai display produk lain.

(7) Windows (jendela)

Jendela merepresentasikan produk yang dijual di toko. Dengan desain dan display yang unik, jendela bisa dijadikan alat untuk menarik konsumen (Levy \& Weitz 2009:520).

Menurut Levy \& Weitz (2009:520) yang perlu diperhatikan dalam menata sebuah jendela toko adalah bahwa yang terpajang di jendela merupakan barang yang juga dijual di toko sehingga konsumen tidak merasa tertipu dengan apa yang dipajang di jendela.

(8) Fitting rooms (ruang ganti)

Retailer yang bergerak dalam bidang fashion umumnya memiliki fitting room untuk mencoba pakaian yang akan dibelinya. Grant (2007) dalam Levy \& Weitz (2009:521) mengatakan bahwa fitting room merupakan tempat yang krusial yang menjadi salah satu penentu keputusan konsumen dalam pembelian. Fitting room dengan suasana yang baik akan menambah nilai dari pengalaman berbelanja.

Levy \& Weitz (2009:520) menambahkan bahwa kondisi fitting room haruslah cukup luas, bersih dan nyaman. 


\section{Visual Merchandising}

Visual merchandising berkaitan dengan penyajian produk dan toko untuk menarik konsumen. Yang termasuk dalam faktor visual merchandising adalah (Levy \& Weitz 2009:527):

a. Fixture

Fixture merupakan rak atau gantungan untuk menaruh produk yang dijual agar dengan mudah dapat diketahui oleh konsumen. Levy \& Weitz (2009:527) menjelaskan fungsi rak salah satunya adalah untuk memperlihatkan produk (display merchandise) serta untuk mendukung traffic flow sehingga konsumen tertarik untuk melihat dan berkeliling ke tiaptiap rak. Levy \& Weitz (2009:527) juga menambahkan penggunaan rak harus serasi dengan tema/desain toko secara keseluruhan.

Terdapat empat jenis fixture yang umum digunakan oleh toko fashion yaitu straight rack, rounder, dan four-way, sedangkan untuk barang lain pada umumnya menggunakan tipe gondola (Levy \& Weitz 2009:527).

b. Presentation techniques

Teknik penyajian menjadi salah satu faktor yang ada dalam visual merchandising. Menurut Levy \& Weitz (2009:528-530) ada beberapa teknik penyajian produk yang bisa diterapkan dalam retail business, antara lain sebagai berikut:

(1) Idea-oriented presentation

Teknik penyajian ini menekankan pada ide atau gagasan produk yang dibuat oleh retailer. Retailer sebisa mungkin menunjukan bagaimana seharusnya produk ini dipakai serta mendeskripsikan bagaimana produk ini terlihat jika sedang digunakan.

(2) Style / item presentation

Style presentation menyajikan produk sesuai dengan tipe dan jenis produk. Tipe ini menurut Levy \& Weitz (2009:529) paling banyak diimplementasikan oleh para retailer. Selain itu Levy \& Weitz (209:529) juga menambahkan style presentation akan memudahkan konsumen mencari barang dalam satu bagian.

Retailer mengumpulkan seluruh barang yang berjenis sama dalam satu bagian, dengan begitu konsumen dapat dengan mudah membandingkan produk yang memiliki jenis sama. Sebagai contoh fashion retailer mengumpulkan kaos lengan panjang dalam satu rak.

(3) Color presentation

Teknik penyajian menggunakan kesamaan warna dari produk yang ada. Penyusunan ini bisa diimplementasikan pada ritel fashion dengan mengurutkan produk berdasarkan warna.

Teknik ini juga bisa mencirikan toko pada image tertentu, sebagai contoh jika suatu fashion retail pria menjual produk untuk digunakan saat suasana formal maka toko tersebut bisa menggunakan warna dominan netral seperti krem atau coklat.

(4) Price lining

Price lining berarti mengurutkan produk berdasarkan harga yang menunjukan klasifikasi produk (Levy \& Weitz 2009:529).

(5) Vertical merchandising

Teknik ini menyajikan produk secara vertikal dengan susunan produk yang sama pada satu garis lurus. Levy \& Weitz (2009:529) menjelaskan bahwa teknik ini didasari pada pergerakan alamiah mata (eye's natural movement) yang selalu melihat secara berurutan dari kiri ke kanan dan dari atas ke bawah.

(6) Tonnage merchandising

Tonnage merchandising merupakan teknik penyajian dimana satu jenis barang dalam jumlah yang banyak dikumpulkan pada satu tempat. Dengan teknik ini retailer 
berusaha untuk meningkatkan citra harga dengan meyakinkan konsumen bahwa stok sedang banyak sehingga harga lebih terjangkau (Levy \& Weitz 2009:529).

(7) Frontal presentation

Teknik penyajian ini menampilkan dan mengekspos produk dengan sangat terbuka (frontal) untuk menarik konsumen. Hal ini bisa dilakukan dengan cara menyajikan produk secara lebih intens. Sebagai contoh retailer membuat replika produk dengan ukuran yang lebih besar dari biasanya atau juga bisa dibuat gambar dengan ukuran yang besar jika ingin meningkatkan penjualan suatu produk.

\section{Kerangka Pemikiran}

Store design menurut Levy \& Weitz (2009:508) mencakup layout, signage, serta feature areas. Layout mencakup susunan bagian toko yang terbagi atas wilayah tertentu yang memisahkan jenis produk atau fungsi tertentu. Signage merupakan penanda suatu produk atau penanda arah yang menunjukan suatu tempat di dalam toko. Feature areas adalah area di dalam toko yang dibentuk agar menarik perhatian konsumen dan juga bisa dijadikan sebagai petunjuk arah bagi konsumen. Feature areas dibagi menjadi entrances (jalan masuk), freestanding display, cash wraps (kasir), end caps, promotional aislelarea (area promosi), walls (tembok), windows (jendela / etalase toko), dan fitting rooms (kamar pas) (Levy \& Weitz 2009:518-521).

Visual merchandising berkaitan dengan penyajian produk dan toko untuk menarik konsumen (Levy \& Weitz 2009:527). Fixture merupakan rak atau gantungan untuk menaruh produk yang dijual agar dengan mudah dapat diketahui oleh konsumen, unsurnya adalah traffic flow dan keselarasan dengan tema. Teknik penyajian Menurut Levy \& Weitz (2009:528-530) terdiri dari Idea-oriented presentation, Style/item presentation, Color presentation, Price lining, Vertical merchandising, Tonnage merchandising, dan Frontal presentation. Sebagai empat distro dengan permintaan terbanyak, Ouval Research, Unk1347, Dloops, dan Black Id akan dibuatkan peta 3 aspek store design dan 2 aspek visual merchandising-nya berdasarkan persepsi konsumen sebagaimana tertera pada gambar 1.

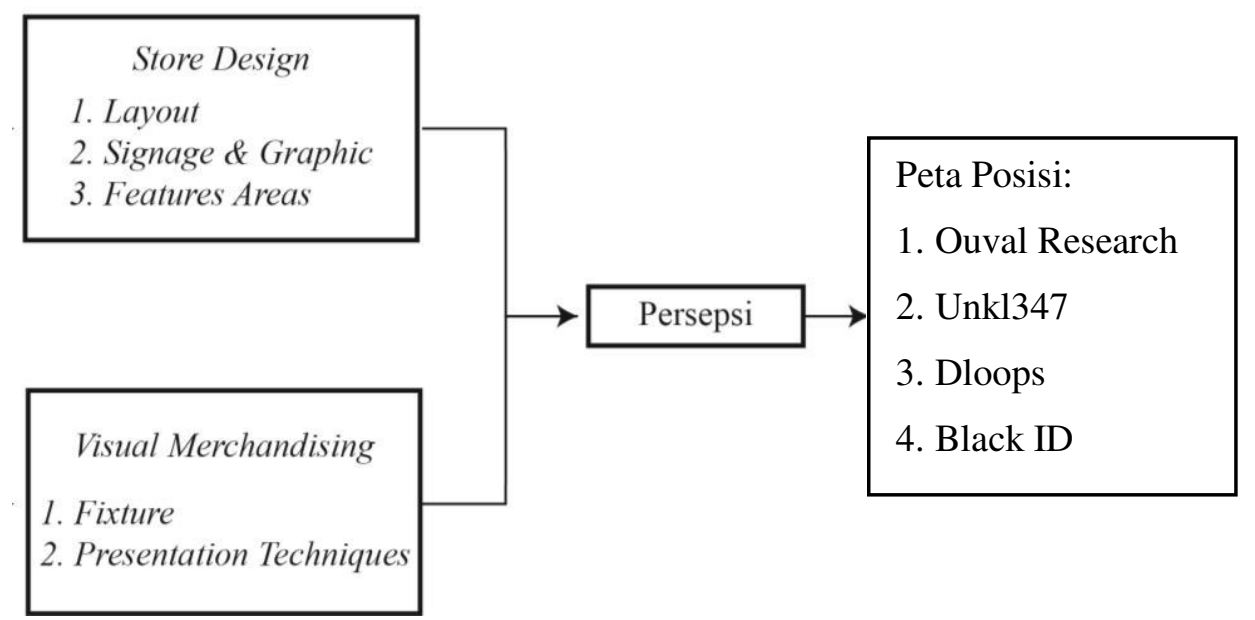

Gambar 1. Kerangka Pemikiran

Sumber: pengolahan data penulis 


\section{METODE PENELITIAN}

Agar dapat membandingkan antara masing-masing store design dan visual merchandising, maka indikator yang diambil dalam penelitian ini merupakan indikator yang sama-sama dimiliki tiap distro yang menjadi objek penelitian. Indikator yang diambil dicocokan dengan kondisi lapangan penerapan store design dan visual merchandising tiap distro. Penjelasan sub variabel dan indikatornya tertera pada tabel 3.

Pada penelitian ini yang menjadi populasi adalah orang yang pernah mengunjungi Ouval Research, Unk1347, Dloops, dan Black Id pada satu tahun terakhir. Dikarenakan populasi tidak diketahui pasti jumlahnya, maka untuk menentukan jumlah sampel yang akan diteliti penulis menggunakan persamaan Bernoulli. Tingkat kepercayaan yang digunakan pada penelitian ini adalah sebesar $95 \%$, tingkat ketelitian ( $\alpha$ ) 5\%. Dari tabel distribusi ditemukan bahwa Error! Reference source not found. $=0,025$ sehingga $Z=1,960$. Tingkat kesalahan ditentukan sebesar 10\% dengan probabilitas kuesioner benar (diterima) atau salah (ditolak) 0,5. Berdasarkan kriteria tersebut, persamaan Bernoulli untuk mencari sampel penelitian ini adalah sebagai berikut:

$$
\begin{gathered}
n \geq \frac{[1,960]^{2} 0,5 \cdot 0,5}{0,1^{2}} \\
n \geq \frac{3,8416 \cdot 0,25}{0,01} \\
n \geq \frac{0,9604}{0,01} \\
n \geq 96,04 \approx 97
\end{gathered}
$$

\begin{tabular}{|c|c|c|}
\hline Variabel & Sub Variabel & Indikator \\
\hline \multirow{9}{*}{ Store Design } & \multirow{3}{*}{ Layout } & Kenyamanan berbelanja \\
\hline & & Kemudahan dalam mencari barang \\
\hline & & Shopping Experience \\
\hline & Signage \& Graphic & $\begin{array}{c}\text { Signage yang merepresentasikan } \\
\text { karakteristik toko }\end{array}$ \\
\hline & \multirow{5}{*}{ Feature Areas } & Entrances \\
\hline & & Cash Wraps \\
\hline & & Promotional Aisle \\
\hline & & Windows \\
\hline & & Fitting Rooms \\
\hline \multirow{4}{*}{$\begin{array}{c}\text { Visual } \\
\text { Merchandising }\end{array}$} & \multirow{2}{*}{ Fixture } & Traffic flow \\
\hline & & Keselarasan dengan tema \\
\hline & \multirow{2}{*}{$\begin{array}{c}\text { Presentation } \\
\text { techniques }\end{array}$} & Kemenarikan teknik penyajian \\
\hline & & Impulse purchase \\
\hline
\end{tabular}

Tabel 3. Variabel Operasional

Sumber: pengolahan data penulis

Hasil dari perhitungan sampel di atas menunjukan jumlah sampel minimum adalah 97 buah yang kemudian penulis bulatkan menjadi 100 buah. 
Teknik pengambilan sampel yang digunakan adalah non-probability sampling dengan menggunakan metode convenience sampling. Teknik pengambilan sampel dengan non-probability sampling menurut Cooper \& Schindler (2011:388) dianggap lebih menghemat biaya. Convenience sampling merupakan pengambilan sampel yang dilakukan secara bebas kepada siapapun yang ditemui. Walaupun convenience sampling tidak memiliki pengawasan untuk memastikan keakuratan, tetapi metode ini masih merupakan prosedur yang dapat digunakan (Cooper \& Schindler 2011:385).

Uji validitas dalam penelitian Multi Dimensional Scaling (MDS) dilakukan dengan memperhatikan R Square (RSQ). Maholtra (1999) dalam Simamora (2005:268) menyebutkan RSQ yang dapat diterima adalah yang lebih besar dari sama dengan 0,6 (RSQ $\geq 0,6$ ). Semakin besar RSQ yang didapat maka semakin baik pula model MDS yang dihasilkan (Simamora, 2005:268). Setelah dilakukan pre test dengan menyebarkan kuesioner kepada 30 responden dan pengolahan data menggunakan SPSS maka didapatkan RSQ = 0,991 yang berarti data yang dihasilkan adalah valid.

Uji reliabilitas dalam penelitian MDS menggunakan stress measure. Hasil data yang dikumpulkan kemudian dibandingkan dengan tabel 4 berikut.

Tabel 4. Indikator Stress

\begin{tabular}{|c|c|}
\hline Stress (persen) & Goodness of Fit \\
\hline 20 & Poor \\
\hline 10 & Fair \\
\hline 5 & Good \\
\hline 2,5 & Excelent \\
\hline 0 & Perfect \\
\hline
\end{tabular}

Sumber: Simamora (2005:269)

Dari hasil pre test yang dilakukan dengan menyebarkan kuesioner kepada 30 responden dan pengolahan data menggunakan SPSS maka didapatkan Stress sebesar 13\% yang berarti fair.

Teknik analisis data menggunakan Multi Dimensional Scaling (MDS) adalah untuk mengetahui persepsi responden terhadap suatu objek dibandingkan dengan objek lain. Penyajian data menggunakan diagram yang memperlihatkan pemetaan persepsi responden. Menurut Hair, Jr et al (2010:568) MDS yang juga biasa disebut perceptual mapping merupakan teknik analisis untuk mengolah pendapat konsumen yang memiliki kesamaan pada bidang multidimensional.

Penelitian ini memaparkan bagaimana tiap distro berkompetisi dalam hal store design dan visual merchandising. Penilaian dilakukan oleh responden untuk membandingkan tiaptiap distro. Hasil dari penelitian ini nantinya akan memaparkan peta persaingan yang terjadi diantara distro berdasarkan atribut store design dan visual merchandising.

Selain akan memperlihatkan peta persaingan masing-masing distro dari segi store design dan visual merchandising, grafik MDS akan memperlihatkan distro mana yang unggul dalam salah satu indikator serta memperlihatkan distro mana yang tidak memiliki penilaian baik dari responden. Penilaian dihitung berdasarkan kedekatan jarak antara indikator dan objek yang digambarkan pada grafik MDS.

Penghitungan jarak dilakukan dengan menggunakan jarak euclidean (euclidean distance). Jarak euclidean dapat menunjukan perbandingan secara pasti jarak antara setiap objek. Menurut Hair, Jr et al (2010:506) euclidean distance adalah cara mengukur panjang garis lurus antara dua objek yang ada di grafik. Berikut rumus euclidean distance menurut Hair, Jr et al (2010:523): 


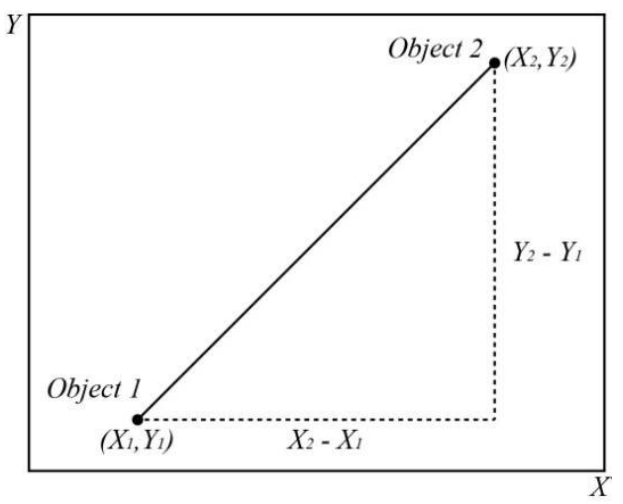

Gambar 2. Euclidean Distance

Sumber: Hair, Jr et al (2010:523)

Dari perhitungan menggunakan rumus tersebut, semakin kecil angka yang dihasilkan maka semakin dekat pula jarak antara objek yang berarti semakin ketat pula persaingannya.

\section{HASIL DAN PEMBAHASAN}

Data yang diolah menghasilkan peta persepsi yang akan memperlihatkan posisi masing-masing objek penelitian dengan variabel store design dan visual merchandising.

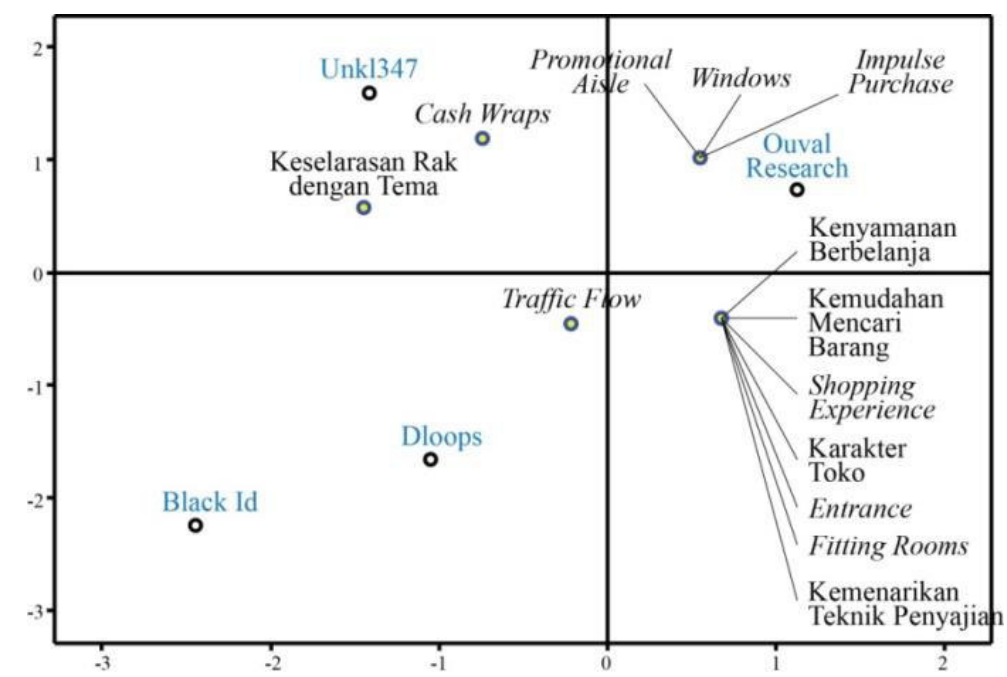

\section{Gambar 3. Peta Persepsi Store Design dan Visual Merchandising Sumber: pengolahan data penulis}

Output yang dihasilkan dari pengolahan data di SPSS 20 merangkum seluruh posisi objek dan item penilaian kedalam satu peta persepsi. Semakin dekat jarak antara objek penelitian dengan titik indikator maka semakin unggul pula objek tersebut pada indikator itu.

\section{Kenyamanan Berbelanja}

Ouval Research dinilai paling unggul dalam hal kenyaman berbelanja yang dihasilkan dari layout yang terbentuk. Dloops dan Unk1347 berada di posisi kedua dan ketiga, sedangkan Black Id berada pada peringkat keempat. 


\section{Kemudahan Mencari Barang}

Dalam indikator ini Ouval Research menempati urutan pertama sebagai distro dengan layout yang paling memudahkan dalam mencari barang. Sementara itu urutan berikutnya ditempati oleh Dloops, Unk1347, serta Black Id.

\section{Shopping Experience}

Pada indikator shopping experience Ouval Research berada pada posisi pertama. Responden menilai layout toko yang diterapkan oleh Ouval Research memberikan pengalaman berbelanja yang paling menyenangkan dibanding ketiga distro yang lain. Posisi dua, tiga, dan empat secara berurut ditempati oleh Dloops, Unk1347, dan Black Id.

\section{Signage yang Merpresentasikan Karakter Toko}

Responden memilih Ouval Research sebagai distro dengan signage yang paling representatif dibanding ketiga distro yang lain. Posisi selanjutnya disusul oleh Dloops, Unk1347, serta Black Id.

\section{Entrance}

Pada indikator entrance responden menilai Ouval Research memiliki desain pintu masuk yang paling mendorong rasa ingin berkunjung ke dalam toko. Ouval Research berada di posisi pertama disusul Dloops, Unk1347 serta Black Id.

\section{Cash Wraps}

Menurut penilaian responden penataan cash wraps yang paling mendorong rasa ingin membeli barang yang dipajang di meja kasir selagi menunggu transaksi adalah Unkl347. Sedangkan posisi dua, tiga, dan empat ditempati oleh Ouval Research, Dloops, serta Black Id.

\section{Promotional Aisle}

Berdasarkan atribut promotional aisle yang paling unggul adalah Ouval Research dengan euclidean distance sebesar 0,6388. Posisi selanjutnya ditempati oleh Unk1347, Dloops, serta Black Id.

\section{Windows}

Dari penilaian responden dapat dilihat bahwa Ouval Research menduduki peringkat pertama dalam indikator windows. Responden menganggap Ouval Research paling unggul dalam menarik konsumen melalui etalase toko. Peringkat kedua, ketiga, dan keempat ditempati Unk1347, Dloops, lalu Black Id.

\section{Fitting Rooms}

Dari keempat distro yang diteliti, responden menilai Ouval Research memiliki fitting room paling nyaman dibanding distro lainnya. Peringkat kedua yang memiliki fitting room ternyaman adalah Dloops, disusul Unk1347, serta Black Id.

\section{Traffic Flow}

Pada indikator traffic flow responden menilai Dloops merupakan distro dengan pengaturan rak yang paling menarik sehingga membuat konsumen memiliki ketertarikan untuk terus berkeliling toko. Posisi dua, tiga, dan empat secara berurut adalah Ouval Research, Unk1347, serta Black ID.

\section{Keselarasan Rak dengan Tema Toko}

Hasil dari penilaian responden terhadap indikator ini adalah bahwa Unkl347 merupakan distro yang dianggap paling memiliki keserasian antara penggunaan rak dengan desain toko. Posisi dua, tiga, dan empat secara berurut diisi oleh Dloops, Ouval Research, dan Black Id .

\section{Kemenarikan Teknik Penyajian}

Penilaian responden memilih Ouval Research sebagai distro yang paling menarik dalam teknik penyajian. Posisi kedua dengan teknik penyajian yang menarik adalah Dloops. Selanjutnya posisi ketiga dan keempat ditempati oleh Unk1347 dan Black Id. 


\section{Impulse Purchase}

Berdasarkan indikator impulse purchase, distro yang paling unggul dalam teknik penyajian yang mendorong rasa ingin membeli adalah Ouval Research. Peringkat dua, tiga, dan empat secara berurut ditempati oleh Unk1347, Dloops, serta Black ID.

\section{Pembahasan}

Pemetaan store design dan visual merchandising berdasarkan persepsi konsumen yang telah dibahas di atas menunjukan keunggulan distro di masing-masing indikator. Peta persepsi terbentuk dari penilaian konsumen terhadap penerapan store design dan visual merchandising distro sesuai fakta di lapangan. Walaupun ada persamaan segmentasi berdasarkan usia, tingkat ekonomi, letak lokasi penjualan, serta konsep yang sama-sama mengusung tema urban, namun tiap distro tetap memiliki perbedaan pada desain produk sesuai ciri khas masing-masing. Selain itu tiap distro juga dapat memiliki segmen yang berbeda dalam hal lain seperti pekerjaan, hobi, komunitas tertentu, dan lain sebagainya.

Secara keseluruhan peta persepsi yang terbentuk sesuai dengan data jumlah permintaan yang disusun oleh Dewi (2010:6). Jika diakumulasikan lalu diurutkan berdasarkan perolehan peringkat satu dalam tiap indikator, maka keempat distro mendapatkan peringkat yang sama dengan peringkat jumlah permintaan seperti tercantum pada Tabel 5.

\section{Tabel 5.}

Perbandingan Jumlah Permintaan dengan Hasil Pemetaan Store Design dan Visual Merchandising

\begin{tabular}{|c|c|c|c|}
\hline No. & Nama Distro & $\begin{array}{c}\text { Jumlah Permintaan } \\
\text { Tahun 2009 (unit) }\end{array}$ & $\begin{array}{c}\text { Akumulasi perolehan peringkat satu } \\
\text { pemetaan store design dan visual } \\
\text { merchandising }\end{array}$ \\
\hline 1 & Ouval Research & 38.401 & 10 Indikator \\
\hline 2 & Unkl 347 & 37.579 & 2 Indikator \\
\hline 3 & Dloops & 36.230 & 1 Indikator \\
\hline 4 & Black Id & 30.237 & 0 Indikator \\
\hline
\end{tabular}

Sumber: Dewi (2010) \& Pengolahan Data Penulis

Unk1347, Dloops, dan Black Id hampir dalam setiap indikator selalu kalah dibandingkan Ouval Research. Hal ini bisa saja terjadi karena Unk1347, Dloops, dan Black Id memiliki segmen khusus yang lebih sempit selain segmentasi berdasarkan usia.

\section{SIMPULAN}

Berdasarkan peta persepsi konsumen mengenai store layout dan visual merchandising:

1. Ouval Research unggul dalam sebagian besar indikator dibanding dengan distro lainnya. Dari 13 indikator yang dinilai oleh responden, ada 10 indikator di mana Ouval Research berada pada posisi pertama sebagai distro yang dipersepsikan lebih baik dibandingkan ketiga distro lainnya, indikator tersebut adalah kenyamanan berbelanja, kemudahan mencari barang, shopping experience, signage yang mewakili karakteristik toko, entrance, promotional aisle, windows, fitting rooms, kemenarikan teknik penyajian, serta impulse purchase.

2. Unk1347 memiliki keunggulan dalam indikator cash wraps serta keselarasan rak dengan tema toko secara keseluruhan, karena dipersepsikan lebih baik dibanding dengan ketiga distro lainnya. 
Penataan cash wraps yang dimiliki Unk1347 dianggap oleh responden adalah yang paling menarik sehingga memunculkan rasa ingin membeli barang yang dipajang dimeja kasir. Hal ini menjadi keuntungan bagi Unk1347 untuk mengoptimalkan profit dari penjualan barang yang dipajang di meja kasir.

3. Berdasarkan 13 indikator yang dinilai, Dloops hanya unggul pada satu indikator yakni traffic flow yaitu pengaturan rak yang paling menarik. Pengaturan rak yang Dloops terapkan dinilai paling membuat konsumen tertarik untuk terus berkeliling toko.

4. Black Id dalam keseluruhan indikator menempati urutan keempat. Pengaturan store design dan visual merchandising yang dilakukan oleh Black Id mendapat penilaian yang paling tidak baik dibanding tiga distro lainnya. Oleh karena itu pada peta persepsi posisi Black Id berada jauh dari seluruh atribut yang dinilai.

5. Berdasarkan akumulasi perolehan peringkat satu dari tiap indikator distro yang dinilai, urutan hasil penelitian ini ternyata sesuai dengan urutan jumlah permintaan distro yang dijelaskan oleh Dewi (2010:6). Ouval Research di peringkat pertama, Unkl347 di peringkat kedua, Dloops di peringkat ketiga, dan Black Id di peringkat keempat. Hasil ini berbanding lurus dengan Teori Levy \& Weitz (2009:507) yang mengatakan bahwa ada pengaruh yang signifikan antara perilaku membeli dengan store design \& visual merchandising. Hasil penelitian ini juga sejalan dengan hasil penelitian Nento (2005:92) dan Stiefi (2012:87) yang mengatakan ada korelasi kuat antara visual merchandising dan store layout dengan minat beli konsumen.

\section{Saran}

Berdasarkan hasil penelitian ini, penulis mengajukan beberapa saran sebagai berikut:

1. Ouval Research hendaknya membenahi pemakaian rak yang saat ini digunakan. Hal ini dikarenakan penilaian responden yang menyatakan bahwa penggunaan rak di Ouval Research kurang sesuai dengan tema toko secara keseluruhan. Dari empat distro yang diteliti, Ouval Research berada di posisi tiga di bawah Unk1347 dan Dloops.

Penyelarasan rak dengan tema toko secara keseluruhan nantinya akan membuat desain toko menjadi lebih berkarakter sehingga pembentukan image dan persepsi konsumen akan menjadi lebih kuat.

2. Unk1347 mendapatkan penilaian yang tidak terlalu baik di delapan indikator. Indikator itu antara lain adalah kenyamanan berbelanja, kemudahan mencari barang, shopping experience, signage yang merepresentasikan karakter toko, entrance, fitting room, traffic flow, serta kemenarikan teknik penyajian. Namun dari keseluruh indikator tersebut Unkl347 sebaiknya terlebih dahulu memperbaiki teknik penyajian produknya agar lebih menarik lagi. Teknik penyajian produk bisa diurutkan misalnya berdasarkan warna agar konsumen lebih tertarik untuk membeli. Selain itu Unk1347 juga hendaknya membenahi layout toko agar dapat memudahkan konsumen dalam mencari barang yang dibutuhkan. Dua perbaikan ini disarankan oleh penulis karena tidak terlalu membutuhkan banyak biaya dan waktu. Dalam jangka panjang tentunya perbaikan secara menyeluruh lebih dianjurkan demi mendapatkan penilaian konsumen yang lebih baik.

3. Dloops memiliki empat indikator yang mendapat penilaian tidak terlalu baik dari konsumen, antara lain cash wraps, promotional aisle, windows, serta impulse purchase. Sebaiknya Dloops terlebih dahulu memperbaiki tempat barang promosi serta penataan barang yang dipajang di meja kasir. Perbaikan tersebut bertujuan untuk memaksimalkan profit dengan mengoptimalkan tampilan barang agar konsumen mau membeli produk yang sedang dalam masa promosi maupun yang dipajang di meja kasir.

4. Black Id adalah satu-satunya distro yang selalu menduduki peringkat empat di setiap indikator. Dalam hal ini pembenahan menyeluruh untuk meningkatkan penilaian konsumen sangat diperlukan. Namun begitu perbaikan jangka pendek yang dapat 
diterapkan adalah melalui pembenahan pada aspek kemudahan mencari barang, kemenarikan teknik penyajian, serta impulse purchase. Ketiga aspek itu hendaknya lebih diperhatikan agar produk yang dipajang tetap menarik untuk dibeli.

5. Walaupun peta persepsi memperlihatkan distro mana yang paling unggul dalam atribut tertentu namun tiap distro harus tetap memperhatikan segmentasi dan target pasar yang dituju sehingga pengembangan store design dan visual merchandising selanjutnya akan tetap terfokus dan tidak terpengaruh oleh pesaing dengan target pasar yang berbeda.

6. Penelitian selanjutnya sebaiknya dilakukan mengenai perumusan strategi store design dan visual merchandising yang diinginkan oleh konsumen serta pemetaan strategi lokasi yang diterapkan distro berdasarkan persepsi konsumen.

\section{DAFTAR REFERENSI}

BPS Kota Bandung. (2013). Kota Bandung Dalam Angka 2013. Bandung: BPS.

BPS Kota Bandung. (2012). Survey Sosial Ekonomi Daerah 2010. Bandung: BPS.

Bank Indonesia. (2008). Pola Pembiayaan Usaha Kecil Distro. Jakarta: Bank Indonesia.

Dewi, Hanni Puspita. (2010). Pengaruh Fitur, Promosi, dan Pangsa Pasar, Terhadap Permintaan Kaos, Kemeja, dan Celana pada Industri Kreatif di Kota Bandung (Studi pada Distro di Kota Bandung). Tugas Akhir UPI: tidak diterbitkan.

Dinas Kebudayaan dan Pariwisata Kota Bandung. (2012). Rekapitulasi Data Potensi Pariwisata di Kota Bandung Tahun 2011 Triwulan IV. Bandung: Disbudpar.

Dinas Koperasi UKM dan Perindustrian Perdagangan Kota Bandung. (2012). Data Potensi Pasar Modern / Pasar Tradisional. Bandung: Dinas KUKM \& Perindag

Cooper, Donald R., \& Schindler, Pamela S. (2011). Business research method (eleventh edition). New York, America: McGraw-Hill Education.

Hair Jr, Joseph F., Black, William C., Babin, Barry J., Anderson, Rolph E. (2010) Multivariate Data Analysis A Global Perspective. New Jersey: Pearson Education Inc.

Levy, Michael., \& Weitz, Barton A. (2009). Retailing Management -7/E. Boston: McGraw Hill-Irwin.

Nento, Prima R. Susanti. (2005). Hubungan Visual Merchandising Display dengan Minat Beli Konsumen (Studi Kasus pada Flexi Center Dago Bandung). Skripsi STMB Bandung: tidak diterbitkan.

Simamora, Bilson. (2005). Analisis Multivariat Pemasaran. Jakarta: PT Gramedia Pustaka Utama.

Stiefi, Deswitha Arvinci. (2012). Pengaruh Store Layout Terhadap Minat Beli (Studi Pada Toko Sepatu Payless di Margocity). Tugas Akhir Universitas Indonesia: tidak diterbitkan. 